\title{
A Discussion about the Impact of Vocational Skills Competition on the Teaching Reform in Vocational Colleges
}

\author{
Guiqin Li \\ Binzhou Polytechnic of Shandong Province in China \\ Binzhou, China
}

\author{
Yanhong Geng \\ Binzhou Polytechnic of Shandong Province in China \\ Binzhou, China
}

\author{
Hongmei Pang \\ Binzhou Medical University in China \\ Binzhou, China
}

\begin{abstract}
Vocational skills competition reflects the requirements to the latest vocational skills in various industries and enterprises. As the propeller of the higher vocational education reform and development in the new period, vocational skills competition can promote the teaching reform in higher vocational colleges. The paper discusses the promoting function of vocational skills competition from the perspective of the specialized course teaching, teachers' level, practice base construction, which will have an important value on the curriculum teaching reform in higher vocational colleges. Reform practice proves that the vocational skills competition plays a great role on the teaching reform in higher vocational colleges.
\end{abstract}

Keywords—vocational skills competition; the teaching reform; higher vocational colleges

\section{INTRODUCTION}

As an important institutional design and innovation in higher vocational education, regularly organized vocational skills competition in China is an important way to select and train high quality workers and high level of skilled personnel, which has been a new educational brand with extensive influence in society. Up to now, after six consecutive sessions, the professions and projects covered by the vocational skills competition increase year by year. During the course of competition, the vocational education activity is becoming more and more diverse, the social attention higher and higher, the participation degree of industry more and more thorough. The implementation of the vocational skills competition promote the development of the teaching reform in higher vocational colleges and accelerate the pace of the connotation construction in vocational colleges.

\section{The Promotion to the SPecialized CourSe REFORM IN HIGHER VOCATIONAL COLLEGES}

Vocational skills competition is organized by the education department and jointly hosted by the relevant industry departments, or authorized by the ministry of education and organized by a certain industry. In order to gear to the needs of registered students and full-time teachers in higher vocational colleges, vocational skills competition explores competition activities for improving students' vocational skills and teachers' teaching skills in accordance with the requirements of specialized courses and the development of corresponding positions. Vocational skills competition is an innovation in the field of higher vocational education in China, which is an important means to promote the development from vocational education to the skill training, and a booster to promote vocational education reform. The specialized course teaching reform is a critical part of vocational education teaching reform. Skills competition is an effective way to promote the specialized course teaching reform. In the specialized course teaching reform, vocational skills competition can promote the reform of teaching content, teaching method, and teaching level, accelerate the construction of teaching resources, and develop students' professional quality.

\section{A. The Promotion to the Teaching Content Reform}

Ministry of education of the people's republic of china[2015] 6 points out, " the deep reform of vocational education should attach teaching close to technological progress and the production practice." Generally speaking, the competition project should be designed according to the actual needs of professional post. The contents and rules of the competition ought to be determined by whether the workrelated tasks can be accomplished successfully. Contestants must be accurate, skillful, and exquisite while participating the competition. Therefore, concerning the issue of curriculum provision, the course description, learning situation design, training content, evaluation standards need to be selected in accordance with the requirements of working ability and skills. More accurately, skillfully and exquisitely the skills competition is completed, skilled jobs, closer the settings of the course contents will be to the actual production. Therefore, vocational skills competition can make teaching content reform more adaptable to the actual production. 


\section{B. The Promotion to the Teaching Method Reform}

Professional skills competition diversifies teaching methods. The traditional third-period teaching practice takes the teacher as the main body, the classroom as the fixed teaching spot, and gives priority to knowledge explanation. These methods are lack of the cultivation of students' enthusiasm and creativity, which leads to students' low learning efficiency and poor work adaptability. Vocational skills competition promotes the transformation from the general traditional teaching methods which focus on knowledge teaching to the method of combining the traditional one with competition teaching. Vocational skills competition promotes the transformation from the general-skills training approaches to the combination of skills training and occupation-ability training approaches. Professional skills competition promotes the transformation from the chapterteaching method to the project-teaching method which combines theory teaching with professional skills teaching. Vocational skills competition sets students' comprehensive strength as evaluation standards, assesses vocational ability in terms of task completion, which better realize the higher vocational education ability training, and the formation of the comprehensive quality.

\section{The Promotion to the Construction of Specialized Teaching Material}

Textbook construction is an important factor affecting the quality of personnel training. Specialized teaching materials often lags behind four to five years from professional development. Some specialized books' update cycle is very long, which already can't adapt to modern social science and technology and the need of talent development. The implementation of the vocational skills competition can't only rely on training contestants with teaching material. To meet the requirements of the competition and achieve good grades, more new contents must be added, such as the latest operation skills and safety knowledge, environmental protection concepts, energy saving measures, psychological quality, humanistic quality, and enterprise culture etc. Therefore, new crafts, new standards, new technologies, new skills must be involved in the teaching material for vocational education to adjust to the market change. Every end of skills competition should be an opportunity for altering and revising the specialized teaching material. All vocational colleges can firmly rely on nation-organized skills competition platform, adjust the professional training scheme, supplement or revise specialized teaching materials to meet the needs of the curriculum implementation.

\section{The Promotion to The TeAching LeVEL}

\section{A. The Promotion to the Transformation and Update of Teachers' Educational Concept}

The National medium and long-term plan for education reform and development (2010-2020) outlines, "with the service as the orientation, with the employment as the guidance, promote the education teaching reform", suggesting that the vocational education should focus on how to the talents' comprehensive quality with the requirements of enterprises in consideration. Vocational skills competition urges teachers to study the competition files, learn the competition contents through going deep into the enterprise, invite experts to the scene guidance, and teach with the standards of enterprise or industry for practical purposes, which is an effective way to solve the disjointed problems of the teaching and practical need, greatly enhance teaching pertinence and practicability, leaves no space to the past teaching three-step model, and will be conducive to the transformation and update of teachers' teaching concept.

\section{B. The Improvement to the Teachers' Practical Skills and the Practical Teaching Ability}

The target of vocational education is to cultivate highquality skilled professionals with good professional ability, and so vocational college teachers is specific performers of the target. Teachers' practical skills and practical teaching ability have a direct bearing on the students' professional quality and professional ability. From the experience of teachers in our college, if professional teachers can lead the competition team, teachers' education teaching ability can be improved obviously. In order to achieve good grades in the competition, the teacher must grasp skilled professional skills, transferring from simply finishing teaching tasks to cooperate with enterprises to explore projects, and supervise students in practical operation so as to put the knowledge into real skills. Through organizing teachers to directly participate and guide students in the skills competition, teachers can comprehensively grasp the enterprises' demand for high-quality skilled talents training and the skill requirements of relevant occupations, and then update teaching concepts, improve teaching methods, which can make vocational education truly integrated with practice, the enterprise, and the society.

\section{The Benefits for the Cultivation and Formation of Teaching Teams}

During the process of preparation, training, evaluation and simulation for vocational skills competition, the teaching team is composed of full-time and part-time teachers. Teachers play the role of supervising while students practicing in person. The demands of competition drive the vocational colleges' relative majors to build their own professional leader, the backbone teachers, full-time teachers and part-time teachers, especially encouraging the highly skilled experts in the frontline positions to form teaching teams.

\section{The Promotion to the CONSTRUCtion of PRACTICE TRAINING BASES}

\section{A. The Promotion to the Campus Construction of Practice Training Bases}

1) Standardization of the training project and enterprization of training content: The aim of vocational education is to cultivate the talents in line with personnel employing standards. To achieve this goal, students need to accomplish training in the production environment similar to the enterprise and perform according to the requirements of producing the real products. However, in the campus 
construction of practice training bases, most of the vocational colleges can't industrialize the practical training base, training sites and training programs can't simulate the real business environment. By attending professional skills competition, from preparation, training to the process of competition, students must operate in accordance with enterprises' work standards, production standards, and evaluation standards. Meanwhile, teachers should also carry out supervision in accordance with the rules of the enterprise guidance. Students handle the same devices as used in enterprises, process products just in the way workers manufacture the products in the enterprises, and eventually are evaluated by criteria for the assessment of enterprise workers. Therefore, vocational skills competition can promote the standardization of training design, and realize enterprization of the training content.

2) nterprization of campus training conditions: Vocational skills competition encourages the vocational colleges to improve the experimental training facilities. The construction of training facilities in the school can be carried out on the basis of the relevant standards in the competition. Considering the real work practice, the construction can introduce the latest equipment to simulate the real environment so as to supply all-round support for skills training. Therefore, vocational skills competition can realize "zero distance" connection between the campus environment and enterprise, and so the school practice equipment and the enterprise.

3) Expanded function of the campus training bases: Most training bases only undertake campus training projects, which leads to its single function without vitality. The limitation of construction funding affects the sustainable development of the practice base. Through the development of the vocational skills competition, the school practice bases won the favor of enterprises, which improved its comprehensive strength and reinforced its scientific research and technical service ability. And it paves the way for non-academic education vocational skills training, professional skill appraisal work, professional research, technology development, production and the new technology application etc.

\section{B. Development of Off-Campus Training Bases and College- Enterprise Training Bases}

College-enterprise cooperation is an effective way to establish a good training base for vocational colleges in order to track the development of industry technology and the latest technology application, and then improve the quality of personnel training. Under the guidance of administration and industry, with the enterprises' participation, the vocational skills competition set up the platform for the co-operation between colleges and enterprises. Enterprises' active participation in all forms can not only extend the influence of the enterprise, lifted its profile, the enterprise can also select technical experts they needed in the competition. The development of the vocational skills competition highlights the characteristics of vocational colleges, enhance mutual understanding between colleges and enterprises, and then help vocational colleges win the trust of the enterprise. Along with the enthusiasm of the enterprise to participate in the school training base construction, on the one hand, enterprises will voluntarily donate equipments into schools, and move production lines into the school; on the other hand, enterprises are willing to become off-campus practice base of vocational colleges, which promotes the sustainable development of the construction of school training bases.

To sum up, vocational skills competition provides us with a direction of vocational teaching reform. Based on the test contents, the test requirements and evaluation standards of national vocational skills competition categories, meanwhile with reference to national vocational skills standards, our teaching team reconstructs curriculum systems, updates the teaching contents, improves teaching methods, optimizes evaluation to realize systematization of working process and the advancement of working tasks. Professional platform of teaching reform has been implemented under the task-driven, project-carrier principles. Vocational skills competition plays a profound role in promoting vocational college education. It can be figured out that there exists mutual needs and mutual promotion between the vocational skills competition and the teaching reform. On the one hand, the achievements of teaching reform need the test of vocational skills competition; on the other hand, continuous deep teaching reform promotes the development of vocational skills competition and the improvement of the students' vocational skills. In the future, vocational skills competition will be more perfect in the field of institutionalization and standardization. Certainly, with vocational skills contest deeply driving the teaching reform, the teaching quality of higher vocational education will be further improved.

\section{ACKNOWLEDGEMENTS}

Shandong province education science and the 12th fiveyear plan, 2015 annual general topics : Vocational skills contest to promote the reform of professional course teaching research --In biological technology and application.

\section{REFERENCES}

[1] Zhihong Nie.Engineering surveying teaching reform practice and thinking .Journal of changsha railway institute( social science edition), 2006(6).

[2] Jing Wei,Hua Lin.About the exploration of improve the quality of construction engineering surveying practice teaching .Education and vocational ,2008(21).

[3] Hong Liu.To promote the comprehensive reform competition In order to reform booster connotation construction --The national vocational skills contest system and vocational education connotative development thinking,China's vocational and technical education,2011(8).

[4] Shulei Li .Pilot vocational education teaching reform Improving the quality of personnel training. China's vocational and technical education ,2012(4).

[5] Zhixian Meng.Some issues of vocational education skills contest .Journal of tianjin vocational colleges jointly ,2011(4).

[6] Binghe Chen.Skills to people the value of research to talents training in higher vocational colleges.China's vocational and technical education,2008(9).

[7] Dongju Liu.Impact on teachers' professional vocational skills competition. Vocational education BBS ,2011(1). 
[8] Haiyang Yu.Vocational skills contest for the construction of teachers team. Manager of tianjin college journal .2011(4). 